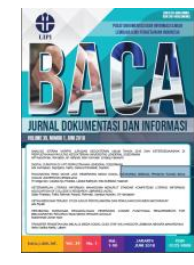

\title{
KAJIAN PERILAKU INFORMASI MAHASISWA FAKULTAS ILMU BUDAYA UNIVERSITAS DIPONEGORO
}

\author{
Yanuar Yoga Prasetyawan ${ }^{1 *}$, Ika Krismayani ${ }^{2}$ \\ ${ }^{1,2}$ Fakultas Ilmu Budaya, Universitas Diponegoro Semarang \\ "Korespondensi: yanuaryoga@live.undip.ac.id
}

Diajukan: 02-07-2019; Direview: 25-03-2019; Diterima: 16-05-2019; Direvisi: 04-08-2019

\begin{abstract}
The aim of this study is to explore the student information behaviors of the Faculty of Humanities, UNDIP. Research uses quantitative methods to describe student behavior in information search. The study found that Google is the most popular site for the students when they are looking for information. However, they still use the primary resources such as academic journals as their main references. The study also found that the students have less used the subscribed academic databases. The identification of students' information behavior is important as it will be used for the enhancement of UNDIP library services. The results of this study can also be used as a library reference for UNDIP in designing user education that will support the improvement of student information search skills.
\end{abstract}

\begin{abstract}
ABSTRAK
Penelitian ini bertujuan untuk mengeksplorasi perilaku informasi Mahasiswa Fakultas Ilmu Budaya UNDIP. Penelitian menggunakan metode kuantitatif untuk mendeskripsikan perilaku mahasiswa dalam mencari informasi. Hasil penelitian menunjukkan bahwa Google menjadi situs paling populer dikalangan mahasiswa sebagai tempat untuk melakukan penelusuran informasi. Meskipun demikian, mahasiswa tetap menggunakan sumber primer seperti jurnal ilmiah sebagai sumber referensi utama mereka. Hasil penelitian juga menunjukan minimnya mahasiswa dalam menggunakan basisdata akademis yang telah dilanggan oleh Perpustakaan UNDIP. Identifikasi perilaku informasi mahasiswa ini penting dilakukan sebagai bahan evaluasi untuk meningkatkan layanan Perpustakaan UNDIP. Hasil penelitian ini juga dapat digunakan sebagai acuan Perpustakaan UNDIP dalam merancang pendidikan pemakai yang akan mendukung peningkatan ketrampilan penelusuran informasi mahasiswa.
\end{abstract}

Keywords: Information behavior; College students; Information retrieval; Diponegoro University

\section{PENDAHULUAN}

Perserta pembelajaran di perguruan tinggi adalah mahasiswa. Kegiatan pembelajaran di perguruan tinggi sudah sepatutnya tidak lagi berpusat pada dosen, namun menggeser tanggung jawab dosen kepada mahasiswa (student learning centre). Karakteristik mahasiswa saat ini memiliki karakteristik digital native. Digital native secara sederhana didefinisikan sebagai "penutur asli" bahasa digital yaitu individu yang akrab dengan dunia digital dan yang lahir dan tumbuh bersama dengan perkembangan teknologi dan komunikasi, hampir semua aktivitas dalam kehidupannya dikelilingi dengan teknologi digital seperti komputer, jaringan internet, smartphone, dsb. (Prensky, 2001).

Kemampuan mahasiswa dalam melakukan mengevaluasi terhadap informasi yang ditemukan telah menjadi sorotan oleh beberapa pakar di bidang ilmu informasi dan perpustakaan (Lee, Paik, \& Joo, 2012; Taylor, 2012). Keberlimpahan sumber daya informasi yang disertai kompleksitas/ rumitnya alat penelusuran informasi di perpustakaan justru mendorong para mahasiswa untuk menggunakan mesin pencari informasi yang lebih dikenal dari pada memilih basis data jurnal ilmiah yang dilanggan oleh perpustakaan. Melalui hasil kajian penelitian diungkapkan bahwa 
mahasiswa gagal memahami tampilan basis data jurnal ilmiah yang dilanggan perpustakaan. Mahasiswa juga tidak mengetahui konten apa saja yang bisa mereka dapatkan dengan memanfaatkan basis data tersebut. Keadaan tersebut diperparah dengan temuan lanjutan yang menyatakan bahwa dalam melakukan penelerusuran informasi mahasiswa tidak memiliki cukup pengetahuan mengenai strategi penelusuran informasi (Georgas, 2013; 2014; 2015).

Fakultas Ilmu Budaya (FIB) Universitas Diponegoro (UNDIP) terdiri dari enam program studi yaitu, Bahasa dan Sastra Indonesia, Bahasa dan Sastra Inggris, Bahasa dan Kebudayaan Jepang, Ilmu Sejarah, Ilmu Perpustakaan, dan Antropologi Sosial. Jika menilik pada visi FIB UNDIP yang mengedepankan kegiatan penelitian, maka sudah menjadi kewajiban bagi program studi mendidik mahasiswanya untuk terlibat aktif dalam kegiatan penelitian. Untuk dapat terlibat aktif maka dibuatlah atmosfer yang mendukung baik dalam proses kegiatan belajar mengajar maupun di luar kegiatan tersebut. Namun hingga kini atmosfer tersebut belum diimbangi dengan upaya membekali mahasiswa dengan kemampuan dasar penelitian yaitu pengetahuan seputar penelusuran informasi.

Berdasarkan hasil observasi awal ditemukan masih banyak Mahasiswa FIB UNDIP yang tidak memperdulikan ketrampilan penelusuran informasi guna menunjang kegiatan penelitian mereka. Pada lain sisi Perpustakaan FIB UNDIP sebagai garda paling depan seharusnya mengajarkan ketrampilan tersebut kepada mahasiswa, belum menaruh perhatian lebih akan pentingnya ketrampilan penelusuran bagi mahasiswa. Peneliti menganggap penting dilakukannya kajian eksplorasi mengenai perilaku informasi.

Georgas, (2013, 2014, 2015) \& Saunders (2018) mengemukakan bahwa individu generasi digital adalah generasi yang terbiasa menggunakan teknologi digital dengan segala kemudahanny. Dalam konteks penelitian ini, generasi digital yang dimaksud adalah mahasiswa. Generasi ini tidak serta merta menjadikan mereka sebagai individu yang awas terhadap informasi, mereka lemah dalam melakukan evaluasi terhadap informasi yang diperoleh. Peneliti mengangap penting dilakukannya kajian perilaku informasi Mahasiswa FIB UNDIP.

\section{TINJAUAN PUSTAKA}

Pembahasan mengenai perilaku informasi terdiri dari beberapa tahapan kegiatan yang berkaitan dengan usaha individu dalam memenuhi kebutuhan informasi. Kebutuhan informasi merupakan faktor pemicu perilaku pencarian informasi (Savolainen, 2017). Kebutuhan informasi dipicu oleh situasi tertentu seperti permasalahan atau kondisi yang menarik untuk dipecahkan/dipenuhi, di bawah pengaruh kondisi kognitif dan emosional individu tersebut. Kondisi tersebut dipengaruhi oleh konteks budaya dan sosial di mana individu beraktivitas dan berinteraksi. Sudut pandang kognitif adalah keinginan individu untuk mendapatkan informasi. Bingkai untuk studi informasi ini meliputi aktivitas temu kembali informasi dan kegiatan mencari beserta interaksinya dalam proses mencapai informasi yang diinginkan (Borlund, 2010). Motivasi dan keingintahuan seorang individu yang tinggi merupakan pengaruh positif terhadap suksesnya pencarian informasi (Borlund \& Dreier, 2014; Ingwersen, 2001).

Seperti yang telah diuraikan pada paragraf sebelumnya mengenai adanya pengaruh kognitif dan emosional dalam kebutuhan informasi, terdapat hal yang menarik ketika melakukan kajian pada para digital native. Pengguna digital native dalam tulisan ini adalah mahasiswa. Dalam penelusuran informasi, mahasiswa cenderung melakukan dengan cara yang termudah dan tercepat guna menyelesaikan tugas atau penelitian mereka, sehingga muncul asumsi bahwa mereka tidak mengalokasikan waktu yang cukup untuk memeriksa lebih lanjut atau mengevaluasi informasi yang diperolehnya. Mereka juga jarang beralih dari halaman pertama pada temuan penelusuran 
dalam aktivitas menyeleksi informasi yang dibutuhkan (Georgas, 2013, 2014, 2015; Dempsey \& Valenti, 2016). Hal tersebut memang menjadi ciri khas yang melekat pada generasi digital yang menginginginkan dan melakukan sesuatu dengan instan.

Todorinova (2015); Bloom \& Deyrup (2015) mengatakan bahwa Google memiliki pengaruh yang besar bagi kebiasaan aktivitas penelusuran informasi mahasiswa dalam rangka menyelesaikan tugas atau kegiatan penelitian. Google menjadi pilihan utama sebagai sumber informasi dari pada sumberdaya informasi perpustakaan. Hal tersebut otomatis menjadi hambatan bagi mereka untuk memahami struktur, kredibilitas, dan evaluasi informasi yang seharusnya mereka perhatikan. Hal tersebut muncul karena adanya perasaan percaya diri mahasiswa terhadap kemampuan penelusuran informasi online mereka melalui Google.

Rasa terlalu percaya diri mahasiswa perlu menjadi perhatian bagi pustakawan. Pustakawan semestinya berperan sebagai pemandu atau konsultan dalam penelusuran informasi. Masalah lain bagi pustakawan, yaitu pustakawan tidak menjadi preferensi pilihan bagi mahasiswa dalam kegiatan konsultasi infomasi tetapi teman kuliah dan dosen yang menjadi pilihan utama mahasiswa untuk berdiskusi dan penelusuran informasi (Miller \& Murillo, 2012). Penelitian ini mengidentifikasi perilaku penelusuran informasi mahasiswa FIB UNDIP yang menghasilkan pola dan kebiasaan pencarian informasi yang dapat menjadi rekomendasi untuk fakultas dan perpustakaan.

\section{METODE}

Objek penelitian adalah Mahasiswa FIB UNDIP yang berstatus aktif pada Semester 5 dan Semester 7. Objek tersebut dipilih dengan pertimbangan bahwa mahasiswa tersebut dinilai telah cukup banyak terlibat dalam kegiatan penelitian. Metode penelitian ini adalah kuantitatif dengan pendekatan survei. Data yang terkumpul kemudian dianalisis menggunakan statistik deskriptif dengan distribusi frekuensi (Morrisan, 2012). Jumlah populasi Mahasiswa FIB UNDIP berstatus aktif pada Semester 5 dan Semester 7 sebanyak 1.161 orang, dan sampel yang diambil sebanyak 116 mahasiswa. Data dikumpulkan dengan kuesioner yang disebarkan ke 10\% Mahasiswa FIB UNDIP terpilih menggunakan teknik sampling. Populasi cenderung homogen maka sampel diambil dengan teknik non-probabilitas yaitu Convenience Sampling (Etikan, 2016). Dari keseluruhan kuesioner yang telah dibagikan kepada responden sampel diketahui hanya 106 kuesioner yang terisi dan dapat diolah lebih lanjut.

\section{HASIL DAN PEMBAHASAN}

Perguruan tinggi dituntut tidak hanya mencetak alumni yang menguasai suatu bidang ilmu pengetahuan saja. Perguruan tinggi juga dituntut untuk mampu memenuhi kewajiban dan fungsinya yang termaktub di dalam tri dharma perguruan tinggi. Salah satu dari tri dharma perguruan tinggi tersebut adalah kegiatan penelitian (Djojodibroto, 2004). Seluruh sivitas akademik, termasuk mahasiswa memiliki kewajiban untuk menghasilkan penelitian yang dapat digunakan dan bermanfaat bagi masyarakat.

FIB UNDIP terdiri dari enam program studi, yaitu: Bahasa dan Sastra Indonesia, Bahasa dan Sastra Inggris, Bahasa dan Kebudayaan Jepang, Ilmu Sejarah, Ilmu Perpustakaan, dan Antropologi Sosial. Visi FIB Undip yang mengedepankan kegiatan penelitian, sudah menjadi kewajiban bagi program studi untuk mendidik mahasiswanya agar terlibat aktif dalam kegiatan penelitian. Agar mahasiswa terlibat aktif dalam penelitian maka dibuatlah atmosfer yang mendukung baik dalam proses kegiatan belajar mengajar maupun di luar kegiatan tersebut. Hingga kini atmosfer tersebut belum diimbangi dengan upaya membekali mahasiswa dengan kemampuan dasar penelitian, yaitu 
pengetahuan seputar penelusuran informasi. Peneliti mencoba untuk mengeksplorasi pengalaman kegiatan penelitian yang dilakukan oleh mahasiswa. Terdapat tiga domain utama yang menjadi kegiatan penelitian mahasiswa, yaitu penyusunan skripsi, proposal skripsi, program kreativitas mahasiswa, dan karya tulis ilmiah. Adapun persebaran datanya dapat dilihat pada Gambar 1.

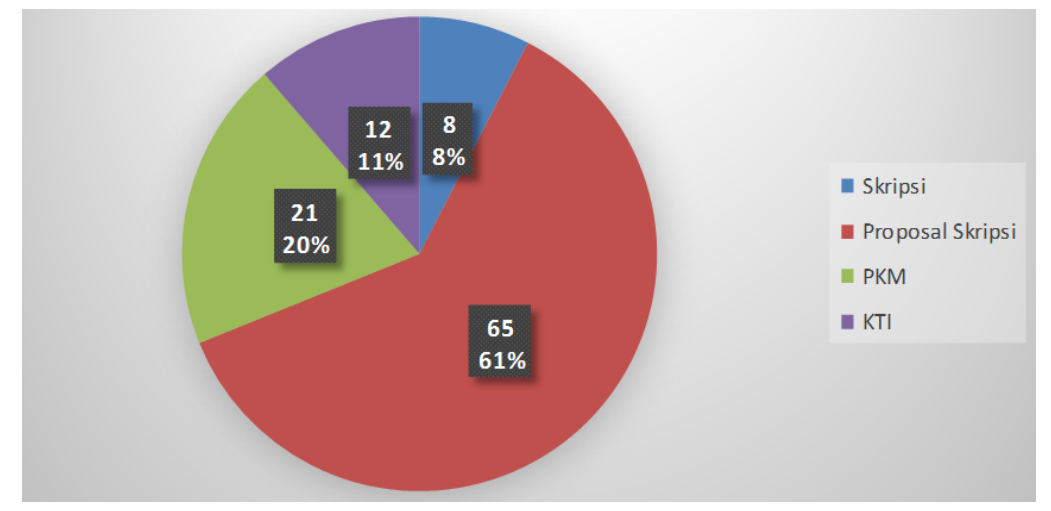

Gambar 1. Sebaran jenis kegiatan mahasiswa

Kegiatan penelitian merupakan sebuah proses individu untuk menguraikan permasalahan dan mencoba mencari solusi terhadap permasalahan yang muncul. Solusi yang ditawarkan seharusnya memenuhi kaidah ilmiah yang berlaku dan tidak berdasarkan egoisme. Rumitnya aktivitas penelitian ini menggiring para mahasiswa untuk berkolaborasi dan berdiskusi dengan orang lain untuk memecahkan berbagai permasalahan. Dari data yang diperoleh muncul 2 domain subjek yang menjadi tempat mahasiswa melakukan konsultasi dan diskusi, yaitu dosen dan teman kuliah. Terdapat $69(65,1 \%)$ mahasiswa yang memilih melakukan konsultasi seputar kegiatan penelitiannya kepada dosen sedangkan 37 (34,9\%) mahasiswa lainnya memilih teman kuliah. Alasan mahasiswa melakukan konsultasi seputar kegiatan penelitiannya kepada dosen karena mahasiswa menilai dosen lebih menguasai tema kajian secara keilmuan serta memiliki pengalaman yang panjang mengenai kegiatan penelitian. Mahasiswa yang melakukan konsultasi kegiatan penelitiannya dengan teman kuliah karena mereka merasa lebih dekat secara personal dan emosional sehingga proses diskusi dapat terlaksana dengan santai dan tanpa rasa malu.

Hasil penelitian menunjukkan bahwa pustakawan masih belum menjadi pilihan utama bagi mahasiswa dalam berkonsultasi seputar penelusuran informasi. Hanya terdapat $7(6,6 \%)$ mahasiswa yang mengandalkan pustakawan dalam hal tersebut. Dosen menjadi pilihan utama mahasiswa dalam konsultasi tentang penelusuran informasi. Terdapat $60(56,6 \%)$ mahasiswa yang mengandalkan dosen dalam aktivitas tersebut, dan selebihnya 39 (36,8\%) mahasiswa merasa lebih nyaman berkonsultasi dengan sesama teman kuliah untuk kegiatan penelusuran informasi tersebut. Hal tersebut dijelaskan pada Gambar 2. 


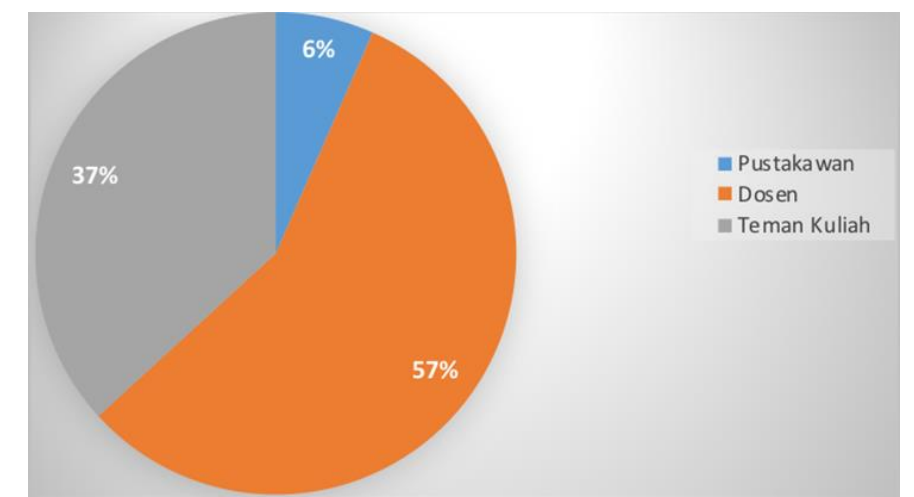

Gambar 2. Preferensi mahasiswa berdikusi dalam kegiatan penelitian

Hasil penelitian juga menunjukkan bahwa lebih dari separuh responden (57 atau 53,8\% mahasiswa) memilih Google sebagai prioritas utama dalam penelusuran informasi. Hanya ada 20 $(18,9 \%)$ mahasiswa yang memiliki preferensi menggunakan database jurnal dan buku yang dilanggan oleh Perpustakaan UNDIP. Minimnya mahasiswa yang menggunakan database jurnal dan buku menunjukkan bahwa mereka masih mempercayakan prioritas referensinya terhadap koleksi buku di perpustakaan. Diketahui masih ada sejumlah 29 mahasiswa $(27,4 \%)$ yang masih setia menggunakan koleksi tercetak di perpustakaan. Gambar 3 menunjukkan informasi mengenai preferensi sumber daya informasi mahasiswa.

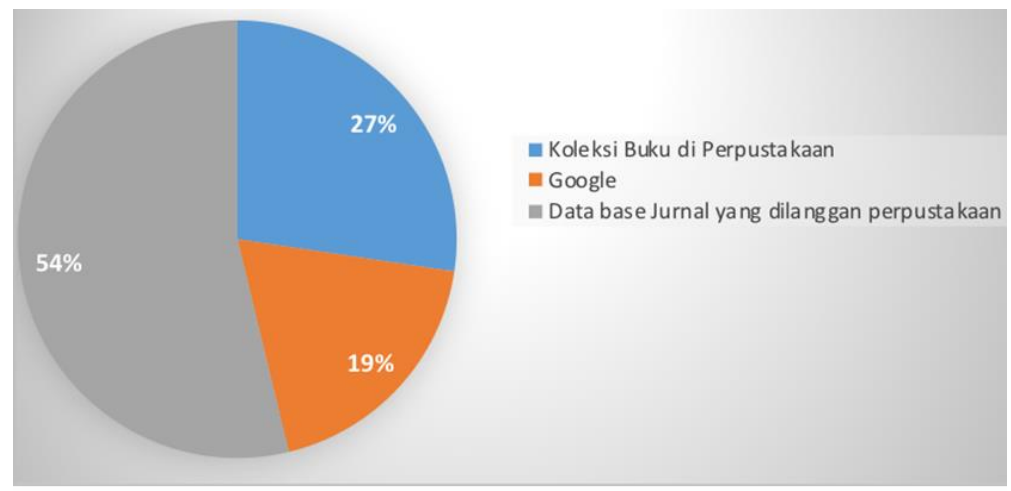

Gambar 3. Sumber daya informasi mahasiswa

Hal tersebut menunjukkan bahwa keterlibatan pustakawan dalam penelitian mahasiswa sebagai konsultan riset yang masih tergolong minim. Pustakawan di perpustakaan perguruan tinggi memiliki peran strategis dalam proses penelitian. Pustakawan tidak hanya dituntut untuk mampu menyediakan literatur yang berfungsi sebagai referensi penelitian, tetapi juga mampu memberikan konsultasi riset, melaksanakan program pengajaran, memiliki kemampuan riset, membantu dalam penerbitan dan penyebarluasan hasil-hasil riset (Andayani, 2016).

Mahasiswa FIB UNDIP memiliki kesadaran dalam memilih lokasi penelusuran informasi melalui internet menunjukan kebiasaan yang baik. Hal tersebut terlihat ketika mahasiswa memilih sumber informasi dengan web domain akademis (45 Mahasiswa/43,7\%) atau web domain pemerintah (4 Mahasiswa/3,9\%). Terdapat 42 mahasiswa (40,8\%) yang menyandarkan acuan referensinya pada Google Scholar. Ada beberapa mahasiswa yang belum memperhatikan kredibilitas sumber informasi yang dirujuknya. Terlihat pada jawaban mahasiswa yang memilih 
web blog (8 Mahasiswa/7,8\%) dan Wikipedia (4 mahasiswa/3,9\%) sebagai referensi karya ilmiah. Hal tersebut terlihat pada Gambar 4.

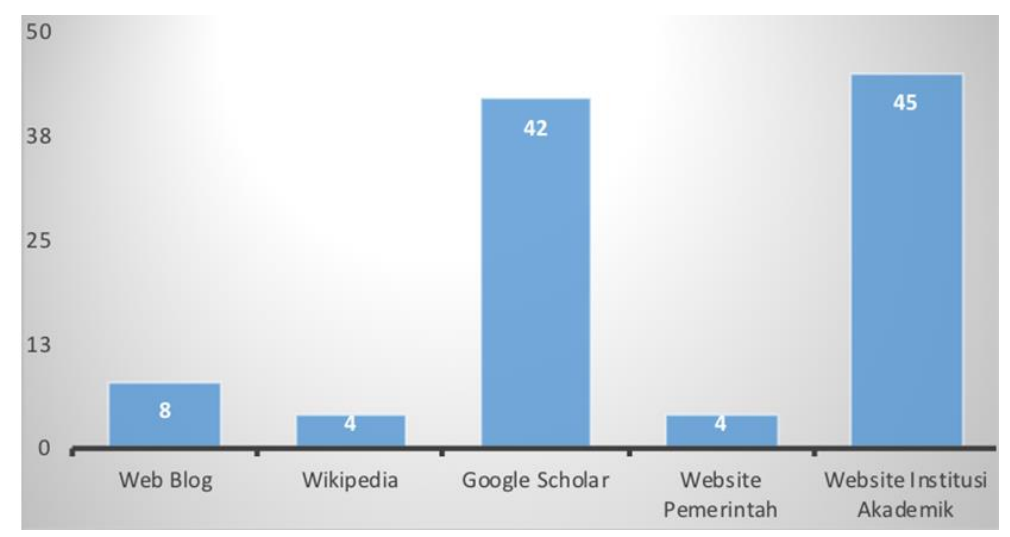

Gambar 4. Preferensi halaman website untuk referensi

Seperti yang dijelaskan pada paragraf sebelumnya mengenai kemudahan penggunaan mesin pencari Google dan kemampuannya untuk mengenali bahasa ilmiah. Ada 39 mahasiswa (37,5\%) yang melakukan penelusuran melalui mesin pencari Google dengan cara hanya memasukkan kata kunci langsung ke dalam menu pencarian Google. Cara atau perilaku penelusuran lain dan cukup terkenal di kalangan mahasiswa adalah dengan membubuhkan keterangan jenis file setelah kata kunci guna memperoleh informasi dengan format file tertentu, hampir separuh dari responden (51 mahasiswa/49\%) menggunakan cara tersebut ketika memanfaatkan mesin pencari Google sebagai tempat penelusuran informasi. Beberapa mahasiswa memberikan contoh formulasi kata kunci dengan cara tersebut, yaitu "jurnal tradisi adat.pdf", "impoliteness strategies theory.pdf", dan "morphopogy of folktales by Propp.pdf". Beberapa mahasiwa juga kreatif memformulasikan kata kunci menggunakan mesin pencari Google. Mereka memberikan keterangan site setelah kata kunci agar fokus pada website tertentu. Ada 12 mahasiswa (11,5\%) yang melakukan cara tersebut. Beberapa mahasiswa memberikan contoh formulasi kata kunci dengan cara tersebut, yaitu "communication technology" site: ac.id. Meskipun mesin pencari Google pada sistem temu balik informasi telah mendukung penggunaan operator bolean. Minimnya pengetahuan Mahasiswa FIB UNDIP mengenai strategi penelusuran sehingga hanya 2 mahasiswa $(1,9 \%)$ yang menggunakan operator bolean melalui Google. Beberapa mahasiswa memberikan contoh formulasi kata kunci dengan cara tersebut yaitu "film pendek + perpustakaan" atau "film pendek AND perpustakaan".

Tim pengembang sitem temu balik informasi selalu mencoba untuk mengembangkan fasilitas pencarian sesuai dengan perilaku pencarian pengguna. Mereka melakukan uji coba trial and error, sampai pada titik tidak ada solusi alternatif lain, dan menemukan cara yang lebih baik untuk digunakan (Morville \& Callender, 2010). Menu pencarian pada database jurnal yang dilanggan oleh UNDIP telah dilengkapi fasilitas autocomplete. Fasilitas autocomplete merupakan fasilitas penunjang kegiatan penelusuran yang memungkinkan search box melengkapi atau mengkoreksi query yang dimasukkan oleh pengguna (kemungkinan ada kesalahan ketik atau pengejaan dapat diminimalisir). Tidak mengherankan jika dari 41 responden yang menggunakan database jurnal berlangganan memilih mengggunakan pencarian dasar (basic search) sebagai salah satu pola penelusuran informasi. Sebagian besar responden (20 mahasiswa/ 49\%) memilih cara tersebut dan 10 mahasiswa (24\%) lebih memilih advance search dan 11 mahasiswa (27\%) menggunakan fasilitas browse by ketika memanfaatkan database jurnal yang dilanggan oleh Perpustakaan 
UNDIP. Konsekuensi menggunakan basic search sebagai strategi pencarian, recall atau dokumen yang berhasil dipanggil oleh sistem temu kembali informasi relatif tinggi, sehingga memaksa penggunanya untuk menginvestasikan waktu yang lebih lama untuk memilih informasi yang relevan dengan kebutuhan informasinya. Gambar 5 menjelaskan tentang persebaran data perilaku mahasiswa dalam pencarian informasi jurnal online.

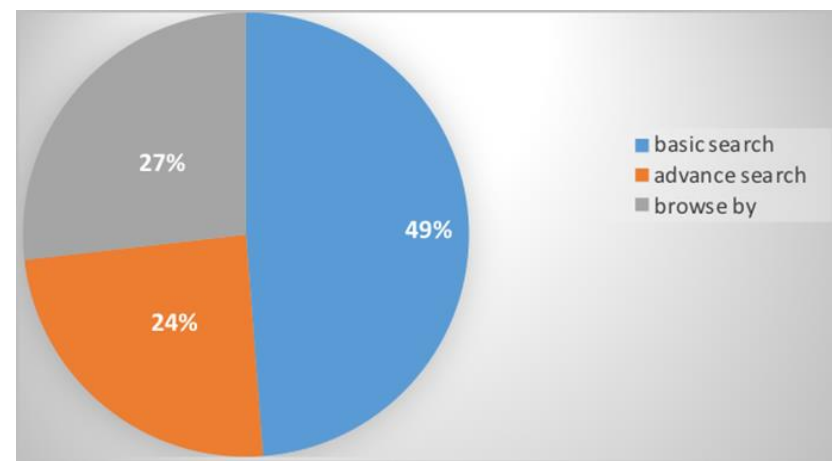

Gambar 5. Perilaku pencarian informasi jurnal online oleh Mahasiswa FIB UNDIP

\section{KESIMPULAN}

Berdasarkan hasil dan pembahasan di atas dapat disimpulkan bahwa Google masih menjadi pilihan utama Mahasiswa FIB UNDIP dalam pencarian sumber daya informasi. Hal tersebut tidak membuat mahasiswa lalai dalam menggunakan sumber primer dalam kegiatan penelitiannya. Pengetahuan Mahasiswa FIB UNDIP dalam memanfaatkan database e-journal berlangganan masih minim. Penelitian ini bermanfaat untuk mengidentifikasi kecenderungan perilaku informasi Mahasiswa FIB UNDIP sehingga perpustakaan dapat menyediakan layanan informasi yang tepat bagi mahasiswa. Hasil penelitian ini diharapkan dapat membantu lembaga dalam memformulasikan kegiatan pendidikan pemakai yang sesuai dengan perilaku pencarian informasi mahasiswa.

Peneliti menyarankan kepada Perpustakaan UNDIP agar memberikan perhatian yang serius terhadap pemanfaatan koleksi. Dalam hal ini perlu ada kerjasama antara pustakawan dengan dosen untuk mengoptimalisasikan pemanfaatan koleksi melalui database e-journal dan e-book yang telah dilanggan. Kerjasama ini dilakukan dengan cara melakukan pendidikan pemakai secara reguler melalui kegiatan perkuliahan. 


\section{DAFTAR PUSTAKA}

Andayani, Ulpah. 2016. Pustakawan Akademik sebagai Mitra Riset di Perguruan Tinggi. AlMaktabah, 15, 29 - 40.

Bloom, B. \& Deyrup, M.M. 2015. The SHU Research Logs: Student Online Search Behaviors Transscripted. Journal of Academic Librarianship, 41, 593-601. http://dx.doi.org/10.1016/j.acalib.2015.07.002.

Borlund, P. 2010. The Cognitive Viewpoint: The Essence of Information Retrieval Interaction. In The Janus Faced Scholar. A Festschrift in Honor of Peter Ingwersen, 23-34. Copenhagen: Royal School of Library and Information Science.

Borlund, P., \& Dreier, S. 2014. An Investigation of The Search Behaviour Associated with Ingwersen's Three Types of Information Needs. Information Processing and Management, 50 (4), 493-507. https://doi.org/10.1016/j.ipm.2014.03.001.

Dempsey, M. \& Valenti, A.M. 2016. Student Use of Keywords and Limiters in Web-scale Discovery Searchin. Journal of Academic Librarianship, Vol.42, 200 - 206.

Djojodibroto, Darmanto. 2004. Tradisi Kehidupan Akademik. Yogyakarta: Galang Press.

Etikan, I. 2016. Comparison of Convenience Sampling and Purposive Sampling. American Journal of Theoretical and Applied Statistics, 5 (1), 1 - 4. https://doi.org/10.11648/j.ajtas.20160501.11.

Georgas, H. 2013. Google Vs the Library: Student Preferences and Perceptions When Doing Research Using Google and a Federated Search Tool. Portal: Libraries and the Academy, 13 (2), 165-185. https://doi.org/10.1353/pla.2013.0011.

Georgas, H. 2014. Google Vs the Library (Part II): Student Search Patterns and Behaviors When Using Google and a Federated Search Tool. Portal: Libraries and the Academy, 14 (4), 503532. https://doi.org/10.1353/pla.2014.0034.

Georgas, H. 2015. Google Vs the Library (Part III): Assessing the Quality of Sources Found by Undergraduates. Portal: Libraries and the Academy, 15 (1), 133-161. https://doi.org/10.1353/pla.2015.0012.

Ingwersen, P. 2001. User in Cotext. In Lectures on Information Retrieval: Third European Summer-School, ESSIR 2000 Varenna, Italy, September 11-15, 2000. Revised Lectures, 157178. Heidelberg: Springer Science \& Business Media.

Lee, J. Y., Paik, W., \& Joo, S. 2012. Information Resource Selection of Undergraduate Students in Academic Search Tasks. Information Research: An International Electronic Journal, 17 (1), 1-19.

Miller, S., \& Murillo, N. 2012.Why Don't Students Ask Librarians for Help? Undergraduate Help-Seeking Behavior in Three Academic Libraries. In L. M. Duke, \& A. D. Asher (Eds.), College Libraries and Student Culture: What We Now Know, 49-70. Chicago: American Library Association.

Morrisan. 2012. Metode Penelitian Survei. Jakarta: Kencana.

Morville, P., \& Callender, J. 2010. Search Patterns: Design for Discovery. Sebastopol: O'Reilly Media. http://searchpatterns.org/.

Prensky, M. 2001. Digital Natives, Digital Immigrants Part 1. On The Horizon, 9 (5), 1-6. 
Saunders, L. 2018. Information Literacy in Practice: Content and Delivery of Library Instruction Tutorials. The Journal of Academic Librarianship. https://doi.org/10.1016/j.acalib.2017.12.022.

Savolainen, R. 2017. Information Need as Trigger and Driver of Information Seeking: A Conceptual Analysis. Aslib Journal of Information Management, 69 (1), 2-21. https://doi.org/10.1108/AJIM-08-2016-0139.

Taylor, A. 2012. A Study of The Information Search Behaviour of The Millennial Generation. Information Research: An International Electronic Journal, 17 (1).

Todorinova, L. 2015. Wikipedia and Undergraduate Research Trajectories. New Library World $116(3), 201-212$. 